\title{
Nephrology Fellowship Training in India: Why is Scenario Different?
}

\author{
Tukaram Jamale* \\ Department of Nephrology, Seth GS Medical College and KEM Hospital, Mumbai, India
}

\begin{abstract}
This short paper gives details about the personal features of Nephrology that attracted the author to the field, and discusses whether these features could remain attractive for the current generation of Nephrology trainees.
\end{abstract}

Keywords: Education, India, teaching, nephrology fellowship.

\section{INTRODUCTION}

Of the six of us who pursued specialty fellowship training after our internal medicine, three (50\%) opted for nephrology and are into practice as nephrologists. This would seem surprising given the current scenario of fellowship positions in nephrology in USA. While thinking on the reasons why I and majority of my colleagues chose nephrology as career following important points came to my mind.

\section{FIRST AND LASTING IMPRESSION}

First impression is considered very important in psychology when one encounters something for the first time. "Amygdala hijack" -wherein smaller and shorter pathway allows the amygdala to receive some direct inputs from environment and start a response before they are fully registered by the neo-cortex [1].

Medical students generally form an impression about various disciplines very early in their training period. I (still painfully) remember the neurophysiology classes from my medical schooldays, which were boring, horrifying and left a permanent negative impact, resulting in hatred towards neurology. A proper introduction to specialty related basic sciences promotes better understanding of the subject and makes learning an enjoyable process. Moreover, it stimulates critical thinking and research.

The introduction to renal physiology should include the process of clinical problem solving sessions. The application of knowledge learned during classroom sessions will automatically generate the necessary interest to pursue nephrology as a career in future. Ideally, both physiologists and clinicians should teach renal physiology courses in medical schools.

\section{“UNLEARNING" AND BUILDING UP QUALITY TEACHING WORKFORCE}

"Unlearning" is considered as one of the most important pre-requisite for true learning. Widely known in psychology

*Address correspondence to this author at the Department of Nephrology, Seth GS Medical College and KEM Hospital, Mumbai, India;

Tel: (91) 022-24107061; Fax: (91) 022-24107405;

E-mail: tukaramjamale@yahoo.co.in as "confirmation bias"-beliefs that one forms early on as a medical student-can be a major deterrent to make correct choices [2]. Two myths that are popular amongst general internists about nephrology:

1) Inherent limited options to treat patients with kidney related problems resulting in poor job satisfaction.

2) Kidney related problems (especially acid base and electrolytes) are complex and difficult to understand.

This is largely due to inadequate introduction to nephrology during internal medicine training. When I started my internal medicine residency, I also shared this belief but only until I was posted in nephrology. In the institute where I trained as an internist, most residents get 4 - 6 months of nephrology training, which includes clinical nephrology, dialysis therapies and basic introduction to renal transplantation. The enthusiasm and inspiration provided by my mentor was the key reason for me to "unlearn" the myths about nephrology and has made learning nephrology (and now teaching), a rewarding experience.

Approaches to complex acid base problems by Halperin et al. are good examples of demystifying nephron-logy education. A good teaching workforce is desperately needed to kindle interest towards nephrology in the future generation.

\section{AN ARTIFICIAL SEPARATION FROM INTERNAL MEDICINE}

Nephrology remains an integral component of internal medicine and to be a successful nephrologist one has to be a good internist.

As an example: Acute kidney injury (AKI) is usually one of the manifestations of the systemic illness such as sepsis, wherein the severity of extra renal organ involvement is usually more important determinant of the final outcome compared to the degree of AKI. Basic skills of the physician in management of sepsis are of paramount importance in caring for these patients. Majority of the earlier nephrologists in India started their career as internists who later developed interest in nephrology. Being astute internists, provided unique opportunity to their trainees to not only learn nephrology but also helped them refine their clinical skills. The combination of factors resulted in providing comprehensive 
patient care and job satisfaction. The changing trends of practice in India, of providing consultative care with primary focus on dialysis support, tends to create monotony in the practice.

Nephrologist should continue to provide primary care support to their patients.

\section{LAGGING BEHIND OTHERS}

Lack of high quality evidence in management of many conditions in nephrology [3] (as compared to critical care or cardiology) makes practice many times subjective giving an impression to trainees that skills involved are difficult to acquire. While nephrology researchers need to work harder, this need not be perceived as deterrent to choose but rather should be highlighted as an opportunity for fellows with research interest to explore many unclear areas in nephrology.

In an environment of fees for service, economic gains play a major role in career choice. With growing privatecorporate health sector providing nephrology service in India, nephrology is viewed as glamorous career option compared to cardiology and critical care. But these trends are unlikely to be permanent hence I haven't considered them.

\section{CONFLICT OF INTEREST}

The author confirms that this article content has no conflict of interest.

\section{ACKNOWLEDGEMENTS}

Declared none.

\section{REFERENCES}

[1] Goleman D. Emotional intelligence: why it can matter more than IQ. New York: Bantam Books 1995.

[2] Oswald ME, Grosjean S. Confirmation Bias. In: Rüdiger PF, Ed. cognitive illusions: a handbook on fallacies and biases in thinking, judgement and memory, Hove. UK: Psychology Press 2004; pp. 79-9.

[3] Samuels JA, Molony DA. Randomised controlled trials in nephrology: state of evidence and critiquing the evidence. Adv Chronic Kidney Dis 2012; 19(1): 40-6. 